\title{
Constructal entransy dissipation rate minimization for a heat generating volume cooled by forced convection
}

\author{
XIAO QingHua, CHEN LinGen* \& SUN FengRui \\ College of Naval Architecture and Power, Naval University of Engineering, Wuhan 430033, China
}

Received March 14, 2011; accepted July 5, 2011

\begin{abstract}
The geometry of a heat generating volume cooled by forced convection is optimized by applying the entransy dissipation extremum principle and constructal theory, while the optimal spacing between the adjacent tubes and the optimal diameter of each tube are obtained based on entransy dissipation rate minimization. The results of this work show that the optimal constructs based on entransy dissipation rate minimization and maximum temperature difference minimization, respectively, are clearly different. For the former, the porosity of the volume of channels allocated to the heat generating volume is $1 / 2$; while for the latter, the larger the porosity is, the better the performance will be. The optimal construct of the former greatly decreases the mean thermal resistance and improves the global heat transfer performance of the system compared with the optimal construct of the latter. This is identical to the essential requirement of the entransy dissipation extremum principle that the required heat transfer temperature difference is minimal with the same heat transfer rate (the given amount of heat generated in the heat generating volume) based on the entransy dissipation extremum principle.
\end{abstract}

entransy dissipation extremum principle, constructal theory, forced convection, entransy dissipation rate, generalized thermodynamic optimization

Citation: Xiao Q H, Chen L G, Sun F R. Constructal entransy dissipation rate minimization for a heat generating volume cooled by forced convection. Chinese Sci Bull, 2011, 56: 2966-2973, doi: 10.1007/s11434-011-4659-9

The necessity to cool electronic devices escalates with the continued increase in chip integration level, packaging density and operating frequency, all leading to a steep increase in the generated heat density. Nowadays, the heat transfer optimization theory involves constructal theory [1-16], entropy generation minimization theory $[11,14,17,18]$ and the field synergy principle [19-26]. Since Bejan studied the development of the street network [1], put forward the constructal theory and applied it to optimization problems involving heat conduction [3], constructal theory has been developing rapidly in simply flow systems [27-37]. Ordonez [27] considered a finite volume that consisted of many heat generating components with uniform rate of internal heat generation and optimized the equidistant internal flow channels that were cooled by natural and forced convection, by using the minimization of maximum tempera-

*Corresponding author (email: lgchenna@yahoo.com; lingenchen@hotmail.com) ture difference as the objective. Bello-Ochende and Bejan [28] enhanced the heat transfer rate by changing the shape of the channels in the heat generating volume. By taking the maximum heat transfer rate as the optimization objective and air as the heat transfer medium, Matos et al. [29,30] adopted staggered finned circular and elliptic tubes for forced convection and obtained the optimal spacing between the tubes. Walsh and Grimes [31] studied the structures of the flow channels to obtain the minimum requirements for forced convection cooling solutions. Muzychka et al. [32] discussed the heat transfer performances of different shapes of micro channels involving parallel plates, rectangles, ellipses, triangles and polygons including their squareness and roundness. Robbe and Sciubba [33] studied the optimal internal cooling geometry of a prismatic slab, and considered four kinds of distribution layout of the channels and their comparative diameters. Kim et al. [34] studied dendritic vascularization for countering intense 
heating from the side to control the maximum temperature of the system, and further considered the transient behavior of vascularized walls exposed to sudden heating [35]. Rocha et al. [36] put forward a constructal optimization method for designing tree-shaped vascular walls in multilayer slabs. Wang et al. [37] designed tree-shaped vascularization and developed a method to control the maximum temperature of the heat generating volume using nothing more than natural convection.

Refs. [27-37] only reflected the temperature limitation of the fins with heat transfer rate maximization (maximum thermal resistance minimization). Guo et al. [26,38] proposed a new physical quantity called "entransy" that describes the heat transfer ability (Ref. [39] referred to it as heat transfer potential capacity) and the entransy dissipation extremum principle to reflect global heat transfer performance. The physical meaning of entransy was further expounded through research into, for example, physical mechanisms of heat conduction and electro-thermal simulation experiments [40,41]. Many scholars [42-59] have shown great interest in and have also studied all kinds of heat transfer optimizations based on entransy dissipation. Wei et al. [60-65], Xie et al. [66-69] and Xiao et al. [70-74] combined the entransy dissipation extremum principle with constructal theory and conducted constructal optimizations for a series of heat transfer problems. Ref. [27] only required that the temperature of the electrical devices' encapsulation should not exceed the temperature limitation, and did not consider how to most effectively remove the heat generated. Consequently, based on Ref. [27], this paper will combine constructal theory with the entransy dissipation extremum principle and re-optimize the uniformly heated volume cooled by forced convection, to obtain the optimal construct corresponding to the minimization of entransy dissipation rate (i.e. best heat transfer performance), and compare it with the construct corresponding to the minimization of maximum temperature difference.

\section{Definition of entransy dissipation rate}

Entransy is a new physical quantity reflecting the heat transfer ability of an object as defined in [38]. The entransy dissipation of a whole volume is deduced as [38]

$$
\dot{E}_{v h \phi}=\int_{v} \dot{E}_{h \phi} d v=\int_{v} \dot{q} \cdot \nabla T \mathrm{~d} v,
$$

where $\dot{q}$ is the thermal current density vector, and $\nabla T$ is the temperature gradient. The equivalent thermal resistance for multi-dimensional heat conduction problems with a specified heat flux boundary condition is given as follows [38]:

$$
R_{h}=\dot{E}_{v h \phi} / \dot{Q}_{h}^{2}
$$

where $\dot{Q}_{h}$ is the thermal current.
The entransy dissipation extremum principle proposed by Guo et al. [38] is stated as follows: for a fixed boundary heat flux, the heat transfer process is optimized when the entransy dissipation is minimized (minimum temperature difference); while for a fixed boundary temperature, the heat transfer process is optimized when the entransy dissipation is maximized (maximum heat flux). The heat transfer problem belongs to the entransy dissipation extremum principle with a fixed boundary heat flux. The smaller the entransy dissipation rate, the better the heat transfer effect. That is, when the entransy dissipation rate is minimized, the mean thermal resistance in the heat transfer process will be minimized and the performance of the system will be optimal.

\section{Structure of the heat generating volume}

As shown in Figure 1, a finite volume that consists of many heat generating components can be regarded as a cuboid control-volume with a uniform rate of internal heat generation. The cuboid volume has a frontal area $A$, length $L$ and heat generation rate $q^{\prime \prime \prime}\left(\mathrm{W} / \mathrm{m}^{3}\right)$ in a solid material of thermal conductivity $k_{s}$. The heat generated is removed from the volume by the coolant in multiple channels cooled by forced convection. The coolant is a single phase fluid with constant specific heat $c_{p}$ and thermal conductivity $k_{f}$. The spacing between tube axes is $S$, and each tube has a length $L$ and a diameter $d$.

One assumes that the arrangement of tube centers is square as shown in Figure 1. The heat generated inside the shaded square with side $S$ is conducted entirely into the flow channel situated at its center. This shaded square element is based on the area $A$ as constructed. The square perimeter



Figure 1 Model of heat generating volume [27]. 
is adiabatic. For ease of analysis [27], the square element can be substituted by a cylindrical element of equivalent diameter $D$ as in Figure 1, and thus, $\pi D^{2} / 4=S^{2}$ and the number of cylindrical elements is

$$
n=\frac{A}{\pi D^{2} / 4}
$$

The cylindrical perimeter is adiabatic with the same temperature. The total heat generated is

$$
q=n q^{\prime \prime \prime} \frac{\pi}{4}\left(D^{2}-d^{2}\right) L
$$

Another simplifying assumption is that each cylindrical element is sufficiently slender $(D<L)$ so that the axial conduction is negligible. That is, the heat generated in each annular cross-section $\left(q^{\prime \prime \prime} \pi\left(D^{2}-d^{2}\right) / 4\right)$ is conducted radially in a solid shell of thickness $(D-d) / 2$. The heat flux $q^{\prime \prime}$ through the tube wall into the fluid can be determined by the following equation:

$$
q=n q^{\prime \prime} \pi d L
$$

\subsection{Large-diameter limit}

The cylindrical element for this extreme condition is shown in Figure 2. The tube diameter $d$ is sufficiently greater than the boundary layer thickness of the coolant so that the temperature difference between the fluid and the tube wall is negligible. The core region of the fluid is still as cold as at the inlet.

The conduction differential equation in the solid shell is

$$
\frac{1}{r} \frac{\mathrm{d} T}{\mathrm{~d} r}+\frac{\mathrm{d}^{2} T}{\mathrm{~d} r^{2}}+\frac{q^{\prime \prime \prime}}{k_{s}}=0
$$

with the boundary conditions:

$$
\left.k_{s} \frac{\mathrm{d} T}{\mathrm{~d} r}\right|_{r=d / 2}=q^{\prime \prime} \text { and }\left.T\right|_{r=d / 2}=T_{w}(x),
$$

where $T_{w}(x)$ is the temperature of the tube wall. By solving the equation one can obtain:

$$
T(x, r)-T_{w}(x)=\frac{q^{\prime \prime \prime}}{2 k_{s}}\left[\frac{D^{2}}{4} \ln \left(\frac{2 r}{d}\right)-\frac{r^{2}}{2}+\frac{d^{2}}{8}\right] .
$$

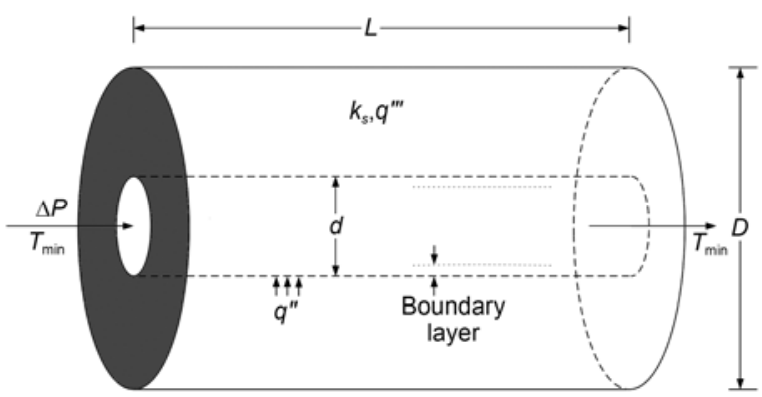

Figure 2 Model of cylindrical element with large-diameter limit [27].
Because the heat flux in the tube wall can be regarded as uniform, the temperature difference of the tube wall is [8]

$$
T_{w}(x)-T_{\min }=\frac{2.208 q^{\prime \prime} x}{k_{f} \operatorname{Pr}^{1 / 3} \operatorname{Re}_{x}^{1 / 2}} \quad\left(\operatorname{Pr} \geqslant 0.5, \operatorname{Re}_{x} \leqslant 5 \times 10^{5}\right),
$$

where $\operatorname{Pr}=v / \alpha, \operatorname{Re}_{x}=U x / v$, and $U$ serves as "free stream" velocity to the boundary layer [27]:

$$
U=\left(\frac{d \Delta P}{2.656 \rho v^{1 / 2} L^{1 / 2}}\right)^{2 / 3} .
$$

The temperature difference of the cylindrical element is

$$
\begin{aligned}
& T(x, r, \theta)-T_{\min } \\
& =\frac{q D^{2}}{4 A k_{f}}\left[3.058 \frac{B e^{-1 / 3} x^{1 / 2}}{d^{4 / 3} L^{1 / 6}}+\frac{d^{2}+2 D^{2} \ln \left(\frac{2 r}{d}\right)-4 r^{2}}{4 \frac{k_{s}}{k_{f}}\left(D^{2}-d^{2}\right) L}\right],
\end{aligned}
$$

where $B e=\frac{\Delta P L^{2}}{\mu \alpha}$ is the dimensionless group pressure drop [27]. The total entransy dissipation rate of the whole volume is

$$
\begin{aligned}
\dot{E}_{v h \phi}= & n \int_{0}^{2 \pi} \int_{0}^{L} \int_{0}^{\frac{D}{2}} q^{\prime \prime \prime} \frac{q D^{2}}{4 A k_{f}} \\
\times & {\left[3.058 \frac{B e^{-1 / 3} x^{1 / 2}}{d^{4 / 3} L^{1 / 6}}+\frac{d^{2}+2 D^{2} \ln \left(\frac{2 r}{d}\right)-4 r^{2}}{4 \frac{k_{s}}{k_{f}}\left(D^{2}-d^{2}\right) L}\right] r \mathrm{~d} r \mathrm{~d} x \mathrm{~d} \theta } \\
= & \frac{q^{2} D^{4}}{4 A\left(D^{2}-d^{2}\right)^{2} d^{4 / 3}}\left\{\frac{2.039\left(D^{2}-d^{2}\right) L^{1 / 3}}{k_{f} B e^{1 / 3}}\right. \\
& \left.+\frac{d^{4 / 3}}{8 k_{s} L}\left[2 d^{2}-3 D^{2}+4 D^{2} \ln \left(\frac{D}{d}\right)\right]\right\}
\end{aligned}
$$

Its corresponding mean thermal resistance $R_{h}$ and mean heat transfer temperature difference $\Delta \bar{T}$ are, respectively, presented as $\dot{E}_{v h \phi} / q^{2}$ and $\dot{E}_{v h \phi} / q$. The mean thermal resistance and mean heat transfer temperature difference are nondimensionalized as

$$
\begin{aligned}
& \tilde{R}_{h}=\frac{R_{h}}{L /\left(A k_{f}\right)} \\
&= \frac{1}{4 \phi(1-\phi)}\left[2.039 B e^{-1 / 3}\left(\frac{d}{L}\right)^{2 / 3}+K\left(\frac{d}{L}\right)^{2}\right], \\
& \Delta \tilde{\bar{T}}=\frac{\Delta \bar{T}}{q L /\left(A k_{f}\right)}=\tilde{R}_{h},
\end{aligned}
$$


where $\phi=d^{2} / D^{2}$ is the porosity of the volume of channels allocated to the total cuboid volume, and

$$
K=\frac{k_{f}}{2 k_{s}}\left[\frac{\ln \phi^{-1 / 2}-1 / 4}{(1-\phi)}-\frac{1}{2}\right] .
$$

The factor in square brackets in eq. (15) is a 1 st order number. In most applications $k_{f} / k_{s}<<1$ [27], so $K$ can be expected to be considerably smaller than 1 . Eq. (13) confirms the expectation that the dimensionless mean thermal resistance keeps increasing with increasingly larger diameter $d$ (or $D)$.

\subsection{Small-diameter limit}

The cylindrical element for this extreme condition is shown in Figure 3. The tube is sufficiently slender, so that its length is covered mainly by fully developed flow and the $N u$ number result [8] (i.e. $N u_{q^{\prime \prime}}=h_{x} d / k_{f}=4.364$ ) in the tube with uniform heat flux is obtained. According to the Newton cooling equation, one can obtain the temperature difference between the tube wall and the core of the fluid at any axial position.

$$
T_{w}(x)-T_{f}(x)=\frac{q^{\prime \prime}}{h_{x}}=\frac{q^{\prime \prime} d}{4.364 k_{f}} .
$$

The first law of thermodynamics yields the differential equation:

$$
\frac{\pi}{4} d^{2} U \rho c_{p} \mathrm{~d} T_{f}=\pi d q^{\prime \prime} \mathrm{d} x
$$

with the boundary conditions:

$$
T_{f}=T_{\min }, x=0 .
$$

In eq. (17) the mean velocity $U$ is [27]

$$
U=\frac{d^{2} \Delta P}{32 \mu L} .
$$

Solving eq. (17) yields the temperature of the fluid:

$$
T_{f}(x)=\frac{128 q^{\prime \prime} L^{3}}{d^{3} B e k_{f}} x+T_{\min } .
$$

The temperature of the solid material of the cylindrical element has the same form as in eq. (8). According to eqs. (8), (16) and (20) one can obtain the temperature difference



Figure 3 Model of cylindrical element with small-diameter limit [27]. of the cylindrical element.

$$
\begin{aligned}
& T(x, r, \theta)=\frac{D^{2} q}{4 A k_{f}} \\
& \times\left[\frac{1}{4.364 L}+\frac{128 L^{2}}{B e d^{4}} x+\frac{d^{2}+2 D^{2} \log \left(\frac{2 r}{d}\right)-4 r^{2}}{4 \frac{k_{s}}{k_{f}} L\left(D^{2}-d^{2}\right)}\right]+T_{\text {min }} .
\end{aligned}
$$

The total entransy dissipation rate of the whole volume is

$$
\begin{aligned}
\dot{E}_{v h \phi} & =n \int_{0}^{2 \pi} \int_{0}^{L} \int_{0}^{\frac{D}{2}} q^{\prime \prime \prime} \frac{D^{2} q}{4 A k_{f}} \\
\times & {\left[\frac{1}{4.364 L}+\frac{128 L^{2}}{B e d^{4}} x+\frac{d^{2}+2 D^{2} \log \left(\frac{2 r}{d}\right)-4 r^{2}}{4 \frac{k_{s}}{k_{f}} L\left(D^{2}-d^{2}\right)}\right] r \mathrm{~d} r \mathrm{~d} x \mathrm{~d} \theta } \\
= & \frac{q^{2} L}{4 A k_{f} \phi(1-\phi)}\left[\frac{64}{B e}\left(\frac{d}{L}\right)^{-2}+\frac{2 \phi-3-2 \ln \phi}{8(1-\phi)} \frac{k_{f}}{k_{s}}\left(\frac{d}{L}\right)^{2}\right. \\
& \left.+\frac{1}{4.364}\left(\frac{d}{L}\right)^{2}\right] .
\end{aligned}
$$

Its corresponding mean thermal resistance $R_{h}$ is presented as $\dot{E}_{v h \phi} / q^{2}$. The mean thermal resistance is nondimensionalized as

$$
\begin{aligned}
\tilde{R}_{h} & =\frac{\dot{E}_{v h \phi}}{q^{2} L /\left(A k_{f}\right)} \\
& =\frac{1}{4 \phi(1-\phi)}\left[\frac{64}{B e}\left(\frac{d}{L}\right)^{-2}+\left(K+\frac{1}{4.364}\right)\left(\frac{d}{L}\right)^{2}\right] .
\end{aligned}
$$

From the above equation, if the following inequality is valid for a much smaller $d / L$ :

$$
\frac{64}{B e}\left(\frac{d}{L}\right)^{-2}>>\left(K+\frac{1}{4.364}\right)\left(\frac{d}{L}\right)^{2},
$$

or

$$
\frac{d}{L}<<\left[\frac{64}{K+0.23}\right]^{1 / 4} B e^{-1 / 4},
$$

in the small-diameter limit eq. (23) can be reduced as

$$
\tilde{R}_{h}=\frac{16}{\phi(1-\phi) B e}\left(\frac{d}{L}\right)^{-2} \text {. }
$$

From [27] one can obtain

$$
\frac{d}{L}<<\left[\frac{128}{0.4}\right]^{1 / 4} B e^{-1 / 4} .
$$


According to the comparison between eqs. (25) and (27), eq. (25) is valid because of the inequality $K<<1$. Eq. (26) confirms the expectation that for the given $\phi$ the dimensionless mean thermal resistance keeps decreasing with increasing diameter $d$ (or $D$ ).

\subsection{Optimal tube diameter and minimum mean thermal resistance}

From the above analyses, in the large-diameter limit, the dimensionless mean thermal resistance keeps increasing with increasing diameter, while in the small-diameter limit, the dimensionless mean thermal resistance keeps decreasing with increasing diameter. Based on the intersection of asymptotes method [27], there exists an optimal tube diameter, $d_{\text {opt }}$, leading to minimum mean thermal resistance. Intersecting the two asymptotes (i.e. eqs. (13) and (26)) yields

$$
\frac{2.039 B e^{2 / 3}}{64}\left(\frac{d}{L}\right)_{\mathrm{opt}}^{8 / 3}+\frac{K B e}{64}\left(\frac{d}{L}\right)_{\mathrm{opt}}^{4}=1 .
$$

Solving eq. (28) yields

$$
B e^{1 / 4}\left(\frac{d}{L}\right)_{\mathrm{opt}}=F(K),
$$

where $F$ is the dimensionless function of $K$ as shown in Figure 4. The optimal tube diameter and its corresponding dimensionless mean thermal resistance are

$$
\left(\frac{d}{L}\right)_{\mathrm{opt}}=F B e^{-1 / 4}
$$

and

$$
\tilde{R}_{h, \mathrm{~m}}=\frac{16 B e^{-1 / 2}}{\phi(1-\phi) F^{2}} .
$$

Eq. (31) shows that $\tilde{R}_{h, \mathrm{~m}}$ first decreases, and then increases with the increase of $\phi$. In other words, there exists an optimal $\phi$ or $D / d$ leading to a minimum $\tilde{R}_{h, \mathrm{~m}}$. By optimizing

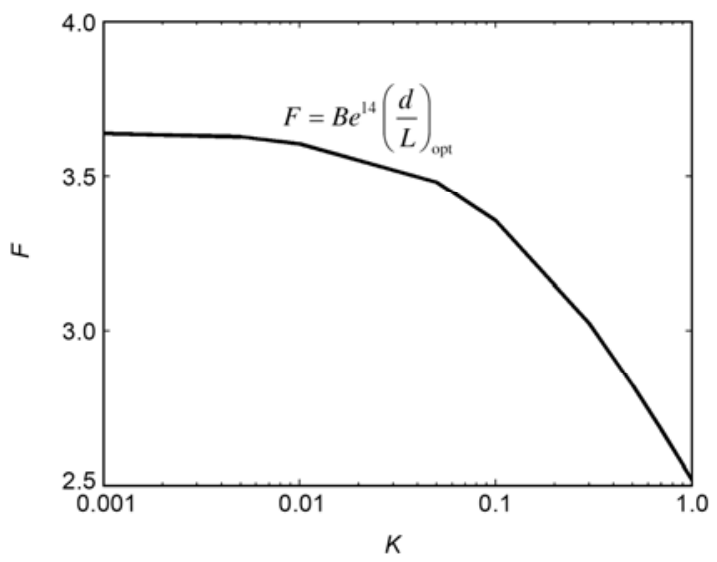

Figure 4 Optimal tube diameter $(d / L)_{\text {opt }}$ for this paper. eq. (31) again one can obtain $\phi_{\mathrm{opt}}$ or $(D / d)_{\mathrm{opt}}$ and its corresponding twice-minimized dimensionless mean thermal resistance as

$$
\begin{gathered}
\phi_{\mathrm{opt}}=1 / 2,(D / d)_{\mathrm{opt}}=\sqrt{2}, \\
\tilde{R}_{h, \mathrm{~mm}}=\frac{64 B e^{-1 / 2}}{F^{2}} .
\end{gathered}
$$

In eqs. (31) and (33), the subscripts, " $\mathrm{m}$ " and " $\mathrm{mm}$ ", denote once-optimized and twice-optimized dimensionless mean thermal resistances, respectively.

\section{Comparison between different optimization objectives}

The optimal tube diameter, $d_{\mathrm{opt}}$, based on the minimization of maximum temperature difference is obtained by the following equation [27]:

$$
\frac{3.057 B e^{2 / 3}}{128}\left(\frac{d}{L}\right)_{\mathrm{opt}}^{8 / 3}+\frac{K^{\prime} B e}{128}\left(\frac{d}{L}\right)_{\mathrm{opt}}^{4}=1,
$$

where $K^{\prime}=\frac{k_{f}}{2 k_{s}}\left(\frac{\ln \phi^{-1 / 2}}{1-\phi}-\frac{1}{2}\right)$. Solving eq. (34) yields

$$
B e^{1 / 4}\left(\frac{d}{L}\right)_{\mathrm{opt}}=F^{\prime}\left(K^{\prime}\right),
$$

where $F^{\prime}$ is the dimensionless function of $K^{\prime}$ as shown in Figure 5. The optimal tube diameter and its corresponding dimensionless mean thermal resistance are

$$
\left(\frac{d}{L}\right)_{\mathrm{opt}}=F^{\prime} B e^{-1 / 4}
$$

and

$$
\tilde{R}_{h, t}=\frac{16 B e^{-1 / 2}}{\phi(1-\phi) F^{\prime 2}} \text {. }
$$

Table 1 lists the optimal constructs based on the minimi-

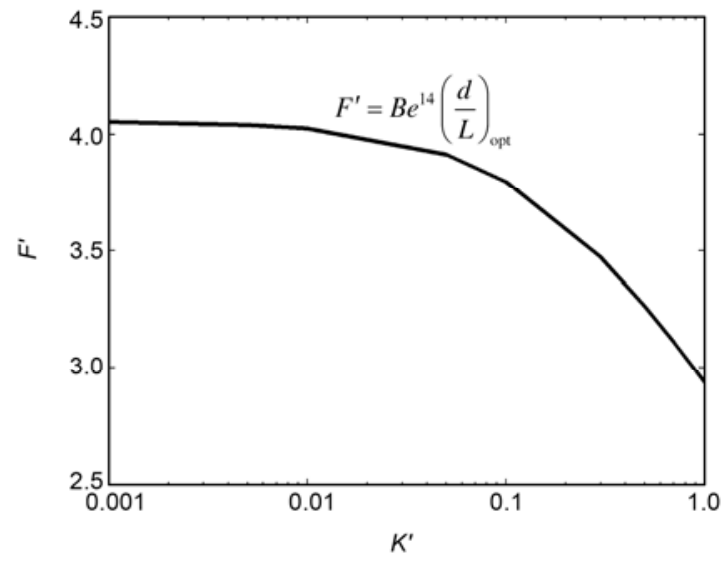

Figure 5 Optimal tube diameter $(d / L)_{\text {opt }}$ from [27]. 
Table 1 Optimal constructs for different optimization objectives

\begin{tabular}{cccc}
\hline Optimization objectives & $(d / L)_{\text {opt }}$ & $(D / d)_{\text {opt }}$ & \multicolumn{1}{c}{$\Delta \tilde{\bar{T}}_{h}$} \\
\hline Minimization of entransy dissipation rate (this paper) & $F B e^{-1 / 4}$ & $\sqrt{2}$ & $64 B e^{-1 / 2} / F^{2}$ \\
Minimization of maximum temperature difference ([27]) & $F^{\prime} B e^{-1 / 4}$ & $\begin{array}{c}\text { Better performance with } \\
\text { even smaller value }\end{array}$ & $\frac{16 B e^{-1 / 2}}{\phi(1-\phi) F^{\prime 2}}$ \\
\hline
\end{tabular}

a) These are derived from [27].

zation of entransy dissipation rates and maximum temperature differences. The results of [27] show that the performance improves as the porosity increases, or as $D / d$ decreases. That is, when the minimization of maximum temperature difference is taken as the optimization objective, the better designs have relatively thin shells of heat generating material, and relatively higher volumetric heat generating rates $\left(q^{\prime \prime \prime}\right)$ for the total heat generation $(q)$. This paper demonstrates the optimal constructal design, i.e. $\phi_{\mathrm{opt}}=1 / 2$ or $(D / d)_{\mathrm{opt}}=\sqrt{2}$.

For visual comparison, $k_{f} / k_{s}=1 / 5$ and $\phi=1 / 5$ are set, and thus, $K=0.02$ and $K^{\prime}=0.05$. Figures 4 and 5 show that $F=$ 3.571 and $F^{\prime}=3.914$ are obtained. The calculations show that the optimal constructs based on entransy dissipation rate minimization and maximum temperature difference minimization are clearly different. The profiles of the optimized cylindrical elements based on entransy dissipation rate minimization and maximum temperature difference minimization are shown in Figure 6. The number of cylindrical elements for the former is much larger than that for the latter. Calculations show that the number of cylindrical elements for the former is 18 times that for the latter. Based on entransy dissipation rate minimization, the mean thermal resistance is decreased by $23.12 \%$, and the heat transfer temperature difference is even smaller. Because the result based on the entransy dissipation extremum principle should be better, the heat transfer performance of the heat generating volume is improved.

\section{Conclusions}

The geometry of the heat generating volume cooled by forced convection is optimized by combining the entransy dissipation extremum principle with constructal theory. The optimal spacing between adjacent tubes and the optimal diameter of each tube are obtained based on the intersection of asymptotes method for minimizing the entransy dissipation rate. The optimized results and optimal constructs based on entransy dissipation rate minimization and maximum temperature difference minimization, respectively, are clearly different. For the former, the optimal design means $\phi_{\text {opt }}=1 / 2$ or $(D / d)_{\text {opt }}=\sqrt{2}$; while for the latter, the better design means an increasing $\phi$ or a decreasing $D / d$. The results show that for the former the optimal construct greatly decreases the mean thermal resistance, and clearly improves

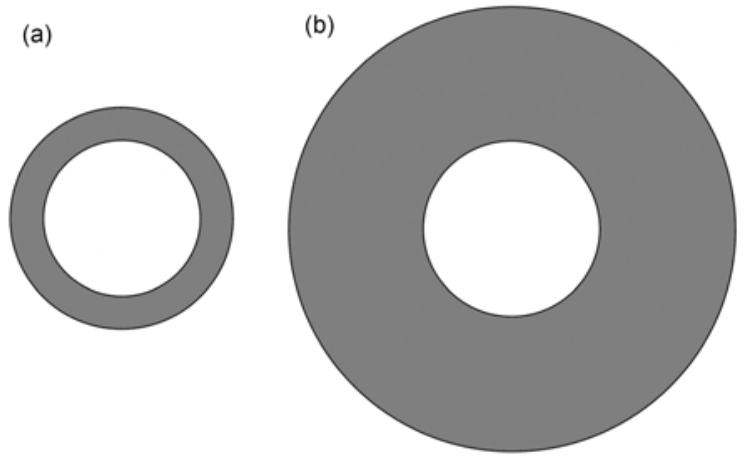

Figure 6 Optimal constructs (profiles of cylindrical elements) based on the two optimization objectives. (a) Minimization of entransy dissipation rate; (b) minimization of maximum temperature difference.

the global heat transfer performance of the heat generating volume. The mean thermal resistance as defined based on entransy dissipation rate reflects the global heat transfer performance. A lower mean thermal resistance means better heat transfer performance, lower mean temperature difference and a higher efficiency of heat transfer. The optimal construct corresponding to the minimization of maximum temperature difference shows the temperature limitation of the encapsulation of the electrical devices cooled by forced convection, does not reflect the global heat transfer performance. In this paper, the optimal construct corresponding to the minimization of entransy dissipation rate reflects the global heat transfer performance, and improves the global heat transfer performance of the system more efficiently. The constructal design corresponding to the minimization of entransy dissipation rate should be adopted for designing heat generating volumes cooled by forced convection when engineering for safe conditions. The work and results provided in this paper enrich the constructal theory and entransy dissipation extremum principle, and further develop the entransy dissipation extremum principle with some significance.

This work was supported by the National Natural Science Foundation of China (10905093), the Program for New Century Excellent Talents in University of China (NCET-04-1006) and the Foundation for Authors of National Excellent Doctoral Dissertations of China (200136).

1 Bejan A. Street network theory of organization in nature. J Adv Trans, 1996, 30: 85-107

2 Bejan A. Shape and Structure, from Engineering to Nature. Cambridge: Cambridge University Press, 2000 
3 Bejan A. Constructal-theory network of conducting paths for cooling a heat generating volume. Trans ASME, J Heat Transfer, 1997, 40: 799-816

4 Zhou S B, Chen L G, Sun F R. Constructal theory: A new direction for generalized thermodynamic optimization (in Chinese). J Thermal Sci Tech, 2004, 3: 283-292

5 Bejan A, Lorente S. The Constructal Law (La Loi Constructale). Paris: L' Harmatan, 2005

6 Bejan A, Lorente S, Miguel A, et al. Along with Constructal Theory. UNIL FGSE Workshop Series No. 1, Hernandez J, Cosinschi M, eds. University of Lausanne, Faculty of Geosciences and the Environment, Switzerland, 2006

7 Bejan A, Merkx G (Editors). Constructal Theory of Social Dynamics. New York: Springer, 2007

8 Bejan A, Lorente S. Design with Constructal Theory. New Jersey: Wiley, 2008

9 Bejan A, Lorente S, Miguel A, et al. Constructal Human Dynamics, Security \& Sustainability. Amsterdam: IOS Press, 2009

$10 \mathrm{Wu}$ W J, Chen L G, Sun F R. Improvement of tree-like network constructal method for heat conduction optimization. Sci China Ser E-Tech Sic, 2006, 49: 332-341

11 Zhou S B, Chen L G, Sun F R. Entropy generation minimization for "volume-point" conduction based on constructal theory (in Chinese). J Thermal Sci Tech, 2007, 6: 294-299

$12 \mathrm{Wu} \mathrm{W}$ J, Chen L G, Sun F R. On the "area to point" flow problem based on constructal theory. Energy Convers Mgmt, 2007, 48: 101-105

13 Zhou S B, Chen L G, Sun F R. Optimization of constructal volumepoint conduction with variable cross-section conducting path. Energy Convers Mgmt, 2007, 48: 106-111

14 Zhou S B, Chen L G, Sun F R. Constructal optimization for solid-gas reactors based on triangular element. Sci China Ser E-Tech Sci, 2008, 51: 1554-1562

15 Xie Z H, Chen L G, Sun F R. Constructal optimization of a vertical insulating wall based on a complex-objective combining heat flow and strength. Sci China-Tech Sci, 2010, 53: 2278-2290

16 Xiao Q H, Chen L G, Sun F R. Constructal optimization for "disc-topoint" heat conduction without the premise of optimized last-order construct. Int J Therm Sci, 2011, 50: 1031-1036

17 Bejan A. Entropy Generation Minimization. New York: Wiley, 1996

18 Chen L G, Wu C, Sun F R. Finite time thermodynamic optimization or entropy generation minimization of energy systems. J Non-Equibri Thermodyn, 1999, 24: 327-359

19 Guo Z Y, Li D Y, Wang B. A novel concept for convective heat transfer enhancement. Int J Heat Mass Transfer, 1998, 41: 2221-2225

20 Guo Z Y. Mechanism and control of convective heat transfer-Coordination of velocity and heat flow fields. Chinese Sci Bull, 2001, 46: 596-599

21 Guo Z Y, Wei S, Cheng X G. A novel method to improve the performance of heat exchanger-Temperature fields coordination of fluids. Chinese Sci Bull, 2004, 49: 111-114

22 Guo Z Y, Tao W, Shah R K. The field synergy (coordination) principle and its applications in enhancing single phase convective heat transfer. Int J Heat Mass Transfer, 2005, 48: 1797-1807

23 Chen Q, Ren J X, Guo Z Y. Fluid flow field synergy principle and its application to drag reduction. Chinese Sci Bull, 2008, 53: 1768-1772

24 Liu W, Liu Z C, Guo Z Y. Physical quantity synergy in laminar flow field of convective heat transfer and analysis of heat transfer enhancement. Chinese Sci Bull, 2009, 54: 3579-3586

25 Liu W, Liu Z C, Huang S Y. Physical quantity synergy in the field of turbulent heat transfer and its analysis for heat transfer enhancement. Chinese Sci Bull, 2010, 55: 2589-2597

26 Li Z X, Guo Z Y. Field Synergy Principle of Heat Convection Optimization (in Chinese). Beijing: Science Press, 2010

27 Ordonez J C. Integrative energy-systems design: System structure from thermodynamic optimization. Disseration for Doctoral Degree. Durham: Duke University, 2003

28 Bello-Ochende T, Bejan A. Fitting the duct to the "body" of the convective flow. Int J Heat Mass Transfer, 2003, 46: 1693-1701
29 Matos R S, Vargas J V C, Laursen T A, et al. Optimally staggered finned circular and elliptic tubes in forced convection. Int $\mathrm{J}$ Heat Mass Transfer, 2004, 47: 1347-1359

30 Matos R S, Laursen T A, Vargas J V C, et al. Three-dimensional optimization of staggered finned circular and elliptic tubes in forced convection. Int J Therm Sci, 2004, 43: 477-487

31 Walsh E J, Grimes R. Constructal theory of the minimum requirements for forced convection cooling solutions. In: Proc 2005 ASME Summer Heat Transfer Confer., July 17-22, 2005, San Francisco, California, USA

32 Muzychka Y S. Constructal design of force convection cooled microchannel heat sinks and heat exchangers. In: ASME Int Conference on Microchannels and Minichannels, June 13-15, 2005, Toronto, Ontario, Canada

33 Robbe M, Sciubba E. Derivation of the optimal internal cooling geometry of a prismatic slab: Comparison of constructal and non-constructal geometries. Energy, 2009, 34: 2167-2174

34 Kim S, Lorente S, Bejan A. Dendritic vascularization for countering intense heating from the side. Int J Heat Mass Transfer, 2008, 51: 5877-5886

35 Kim S, Lorente S, Bejan A. Transient behavior of vascularized walls exposed to sudden heating. Int J Therm Sci, 2009, 48: 2046-2052

36 Rocha L A O, Lorente S, Bejan A. Tree-shaped vascular wall designs for localized intense cooling. Int J Heat Mass Transfer, 2009, 52: 4535-4544

37 Wang K M, Lorente S, Bejan A. The transient response of vascular composites cooled with grids and radial channels. Int $\mathrm{J}$ Heat Mass Transfer, 2009, 52: 4175-4183

38 Guo Z Y, Zhu H Y, Liang X G. Entransy-A physical quantity describing heat transfer ability. Int J Heat Mass Transfer, 2007, 50: 2545-2556

39 Guo Z Y, Cheng X G, Xia Z Z. Least dissipation principle of heat transport potential capacity and its application in heat conduction optimization. Chinese Sci Bull, 2003, 48: 406-410

40 Han G Z, Zhu H Y, Cheng X G, et al. Transfer similarity among heat conduction, elastic motion and electric conduction (in Chinese). J Eng Thermophys, 2005, 26: 1022-1024

41 Han G Z, Guo Z Y. Physical mechanism of heat conduction ability dissipation and its analytical expression (in Chinese). Proc CSEE, 2007, 27: 98-102

42 Zhu H Y, Chen Z J, Guo Z Y. Electricity and thermal analogous experimental study for entransy dissipation extreme principle (in Chinese). Prog Nat Sci, 2007, 17: 1692-1698

43 Liu H B, Guo Z Y, Meng J A. Analyses for entransy dissipation and heat resistance in heat exchangers (in Chinese). Prog Nat Sci, 2008, 18: 1186-1190

44 Chen Q, Ren J X. Generalized thermal resistance for convective heat transfer and its relation to entransy dissipation. Chinese Sci Bull, 2008, 53: 3753-3761

45 Liu X B, Meng J A, Guo Z Y. Entropy generation extremum and entransy dissipation extremum for heat exchanger optimization. Chinese Sci Bull, 2009, 54: 943-947

46 Liu X B, Guo Z Y. A novel method for heat exchanger analysis (in Chinese). Acta Phys Sin, 2009, 58: 4766-4771

$47 \mathrm{Wu} \mathrm{J}$, Liang X G. Application of entransy dissipation extremum principle in radiative heat transfer optimization. Sci China Ser E-Tech Sci, 2008, 51: 1306-1314

$48 \mathrm{Hu} \mathrm{T}$, Min J C, Song Y Z. Analysis of the effects of the heat of sorption on the process of heat transfer in moisture exchange across a membrane. Sci China Ser E-Tech Sci, 2008, 51: 2120-2127

49 Cheng X T, Xu X H, Liang X G. Homogenization of temperature field and temperature gradient field. Sci China Ser E-Tech Sci, 2009, 52: 2937-2942

50 Wang S P, Chen Q L, Zhang J B, et al. A general theoretical principle for single-phase convective heat transfer enhancement. Sci China Ser E-Tech Sci, 2009, 52: 3521-3526

51 Chen Q, Ren J X, Guo Z Y. The extremum principle of mass entransy dissipation and its application to decontamination ventilation designs in space station cabins. Chinese Sci Bull, 2009, 54: 2862-2870 
52 Wang S P, Chen Q L, Zhang B J. An equation of entransy and its application. Chinese Sci Bull, 2009, 54: 3572-3578

53 Xia S J, Chen L G, Sun F R. Optimization for entransy dissipation minimization in heat exchanger. Chinese Sci Bull, 2009, 54: 3587-3595

54 Guo J F, Cheng L, Xu M T. Entransy dissipation number and its application to heat exchanger performance evaluation. Chinese Sci Bull, 2009, 54: 2708-2713

55 Chen L, Chen Q, Li Z, et al. Moisture transfer resistance method for liquid desiccant dehumidification analysis and optimization. Chinese Sci Bull, 2010, 55: 1445-1453

56 Guo J F, Xu M T, Cheng L. Principle of equipartition of entransy dissipation for heat exchanger design. Sci China Tech Sci, 2010, 53: 1309-1314

57 Xia S J, Chen L G, Sun F R. Entransy dissipation minimization for liquid-solid phase processes. Sci China Tech Sci, 2010, 53: 960-968

58 Xia S J, Chen L G, Sun F R. Optimal paths for minimizing entransy dissipation during heat transfer processes with generalized radiative heat transfer law. Appl Math Modell, 2010, 34: 2242-2255

59 Guo Z Y, Liu X B, Tao W, et al. Effectiveness-thermal resistance method for heat exchanger design and analysis, Int $\mathrm{J}$ Heat Mass Transfer, 2010, 53: 2877-2884

60 Wei S H, Chen L G, Sun F R. "Volume-point" heat conduction constructal optimization with entransy dissipation minimization objective based on rectangular element. Sci China Ser E-Tech Sci, 2008, 51: 1283-1295

61 Wei S H, Chen L G, Sun F R. Constructal entransy dissipation minimization for "volume-point" heat conduction based on triangular element. Thermal Sci, 2010, 14: 1075-1088

62 Wei S H, Chen L G, Sun F R. Constructal entransy dissipation minimization for "volume-point" heat conduction without the premise of optimized last-order construct. Int J Exergy, 2010, 7: 627-639

63 Wei S H, Chen L G, Sun F R. Constructal optimization of discrete and continuous variable cross-section conducting path based on entransy dissipation rate minimization. Sci China Tech Sci, 2010, 53: 1666-1677
64 Wei S H, Chen L G, Sun F R. Constructal multidisciplinary optimization of electromagnet based on entransy dissipation minimization. Sci China Ser E-Tech Sci, 2009, 52: 2981-2989

65 Wei S H, Chen L G, Sun F R. Constructal complex-objective optimization of electromagnet based on magnetic induction and maximum temperature difference. Rev Mexi Fis, 2010, 56: 245-250

66 Xie Z H, Chen L G, Sun F R. Constructal optimization for geometry of cavity by taking entransy dissipation minimization as objective. Sci China Ser E-Tech Sci, 2009, 52: 3504-3513

67 Xie Z H, Chen L G, Sun F R. Constructal optimization on T-shaped cavity based on entransy dissipation minimization. Chinese Sci Bull, 2009, 54: 4418-4427

68 Xie Z H, Chen L G, Sun F R. Geometry optimization of T-shaped cavities according to constructal theory. Math Comp Modell, 2010, 52: $1538-1546$

69 Xie Z H, Chen L G, Sun F R. Comparative study on constructal optimizations of T-shaped fin based on entransy dissipation rate minimization and maximum thermal resistance minimization. Sci China Tech Sci, 2011, 54: 1249-1258

70 Xiao Q H, Chen L G, Sun F R. Constructal entransy dissipation rate minimization for "disc-to-point" heat conduction. Chinese Sci Bull, 2011, 56: 102-112

71 Xiao Q H, Chen L G, Sun F R. Constructal entransy dissipation rate and flow-resistance minimizations for cooling channels. Sci China Tech Sci, 2010, 53: 2458-2468

72 Xiao Q H, Chen L G, Sun F R. Constructal entransy dissipation rate minimization for umbrella-shaped assembly of cylindrical fins. Sci China Tech Sci, 2011, 54: 211-219

73 Xiao Q H, Chen L G, Sun F R. Constructal entransy dissipation rate minimization for heat conduction based on a tapered element. Chinese Sci Bull, 2011, 56: 2400-2410

74 Xiao Q H, Chen L G, Sun F R. Constructal design for a steam generator based on entransy dissipation extremum principle. Sci China Tech Sci, 2011, 54: 1462-1468

Open Access This article is distributed under the terms of the Creative Commons Attribution License which permits any use, distribution, and reproduction in any medium, provided the original author(s) and source are credited. 